\title{
The Prolyl Peptidyl Isomerase Pin1 as a Potential Therapeutic Target in Atherosclerosis
}

\section{Narin Osman and Peter $\mathrm{J}$ Little*}

Discipline of Pharmacy, School of Medical Sciences and Diabetes Complications Group, Metabolism, Exercise and Disease Program, Health Innovations Research Institute, RMIT University, Melbourne, Victoria 3083 Australia

Atherosclerosis is the major underlying pathology of cardiovascular disease which is in turn the largest cause of premature mortality in developed countries [1]. Rising obesity and diabetes rates are associated with factors that greatly accelerate the development of coronary artery and other macrovascular diseases. The major areas of investigation of atherosclerosis are focused on the initial pre-inflammatory stage in which atherogenic lipoproteins are trapped in the vessel wall by modified proteoglycans, the inflammatory stage in which immune cells penetrate the vessel wall accumulate cholesterol debris and generate atherosclerotic plaques and the final stage in which plaques rupture precipitating the lethal clinical event $[2,3]$. The initial stage depends upon the action of growth factors to stimulate hyperelongation of chondroitin sulfate/dermatan sulfate glycosaminoglycan (GAG) chains on the small lipid binding proteoglycan biglycan [4]. This is associated in vivo with the elevated expression of GAG synthesizing enzymes in mouse models of atherosclerosis [5]. Transforming Growth Factor (TGF) $-\beta$ is closely associated with the development of atherosclerosis and it is an important modifier of GAG structure [6,7]. TGF- $\beta$ signals via serine/threonine phosphorylation of Smad transcription factors $[8,9]$. This pathway is involved in proteoglycan synthesis in vascular smooth muscle cells [10] and also induces growth in fibroblasts [11]. Phosphorylation of Smad2/3 can occur directly in the carboxy terminus and indirectly in its linker region [12]. These phosphorylation sites in the linker region of $S m a d 2 / 3$ provide potential sites for the action of the prolyl peptidyl isomerase, Pin-1. Pin-1 is being investigated for its potential as a therapeutic target in cancer [13] but it might also in this context be a therapeutic target in cardiovascular disease.

Pin1, a member of theparvulin family of peptidyl prolyl isomerases, has a unique preference for binding via its $\mathrm{N}$-terminal WW domain to phosphorylated-serine/proline or -threonine/proline sequences in proteins. The unique Pin1 C-terminal catalytic domain subsequently catalyses a cis or trans isomerisation of the bound protein. The prolyl isomerisation is a rate-limiting step in protein folding and induces conformational changes, leading to distinct effects in different target proteins, including increased stability or turnover, changes in sensitivity to phosphatases, altered enzymatic activity or subcellular localization, and enabling different ligand protein interactions. Over 30 Pin 1 targets have been identified $[5,14,15]$. Pin 1 is overexpressed in many cancers and is associated with transformation and uncontrolled cell growth, Alzheimer's disease and asthma [14,15]. Pin1 is a significant component of TGF- $\beta$ signalling. TGF- $\beta$ signals can regulate cell proliferation, differentiation, migration and apoptosis all known to be important processes in the pathogenesis of atherosclerosis. A role for TGF- $\beta$ in neointimal hyperplasia of early atherosclerosis is well established [16]. Receptor Smad transcription factors Smad2 and Smad 3 are critical signalling components of the TGF- $\beta$ signal cascade that result in regulation of gene transcription. A Pin 1 binding motif in the linker region of Smad3 at threonine residue 179 is phosphorylated by kinases CDK8/9 in response to TGF- $\beta$ [17] and binds the WW domain of Pin 1 to generate maximum transcriptional activity of genes involved in promoting TGF- $\beta$ mediated migration and invasion [18]. Pin1 is also involved in intimal hyperplasia via regulation of the antioxidant enzyme hemeoxygenase-1 and in vascular smooth muscle proliferation [19]. Overexpression of Pin1 in vascular smooth muscle cells reduces nuclear levels of nuclear factor E2-related factor-2 via induction of ubiquitinylation and thereby decreases the levels of hemeoxygenase-1 and subsequent neointimal formation [19].

Recently it has been shown that Pin 1 catalyses protein isomerisation of activated Protein Kinase C (PKC) [11,20]. The pro-atherogenic effects of activated PKC in vascular smooth cells and endothelial cells are well-known. A number ofcritical cell surface receptor signalling pathways activate PKC including the receptor for endothelin, a G protein coupled receptor and the receptor for PDGF a protein tyrosine kinase receptor. Both receptor signalling cascades lead to atherogenic changes in the extracellular matrix of the blood vessel wall particularly changes to the lipid binding glycosaminoglycan chains of proteoglycans $[21,20]$. Other important atherogenic vascular changes induced by agonist induced PKC activation include increases in contractility [22], extracellular matrix deposition [23] and cellular hypertrophy and proliferation.Pin 1 binding and isomerisation to the trans configuration of activated conventional PKC isozymes results in down-regulation of their PKC expression and activity as a result of ubiquitinylation and degradation. Pin 1 acts as a molecular timer to determine the cellular lifetime of the active conventional isozymes, in contrast the novel PKCisozymes are already in the trans configuration and are bypassed by Pin1 [11]. The length of time active PKCisozymes are able to signal will have significant impact on subsequent signalling outputs thereby influencing atherogenic changes in susceptible cells. Pin1 catalysed isomerisation of $\mathrm{PKC}$ thus adds an additional post-translation protein modification that significantly impacts on its downstream signalling pathways in concert with the more well-known and fully described phosphorylation and dephosphorylation events. Cis-trans isomerase Pin1 is increasingly being recognised as a key component of growth factor signalling pathways. Pin 1 causes important changes in a number of crucial signalling elements and warrants detailed studies of its actions and roles in vascular biology and particularly in the development of atherosclerosis. Its relevance as a potential target in the prevention of the development of atherosclerosis needs to be fully explored.

\section{References}

1. Hozawa A, Folsom AR, Sharrett AR, Chambless LE (2007) Absolute and attributable risks of cardiovascular disease incidence in relation to optimal and

*Corresponding author: Peter J Little, Discipline of Pharmacy, School of Medical Sciences and Diabetes Complications Group, Health Innovations Research Institute, RMIT University, Melbourne, Victoria 3083 Australia; Tel: 61-3-99256686; E-mail: peter.little@rmit.edu.au

Received October 18, 2012; Accepted October 21, 2012; Published October 24 2012

Citation: Osman N, Little PJ (2012) The Prolyl Peptidyl Isomerase Pin1 as a Potential Therapeutic Target in Atherosclerosis. Clin Exp Pharmacol 2:e109. doi:10.4172/2161-1459.1000e109

Copyright: $\odot 2012$ Osman N, et al. This is an open-access article distributed under the terms of the Creative Commons Attribution License, which permits unrestricted use, distribution, and reproduction in any medium, provided the original author and source are credited. 
Citation: Osman N, Little PJ (2012) The Prolyl Peptidyl Isomerase Pin1 as a Potential Therapeutic Target in Atherosclerosis. Clin Exp Pharmacol 2:e109. doi:10.4172/2161-1459.1000e109

borderline risk factors: comparison of African American with white subjects-Atherosclerosis Risk in Communities Study. Arch Intern Med 167: 573-579.

2. Falk E (1989) Morphologic features of unstable atherothrombotic plaques underlying acute coronary syndromes. Am J Cardiol 63: 114E-120E.

3. Davies MJ (1996) Stability and instability: two faces of coronary atherosclerosis. The Paul Dudley White Lecture 1995. Circulation 94: 2013-2020.

4. Little PJ, Osman N, O'Brien KD (2008) Hyperelongated biglycan: the surreptitious initiator of atherosclerosis. Curr Opin Lipidol 19: 448-454.

5. Anggraeni VY, Emoto N, Yagi K, Mayasari DS, Nakayama K, et al. (2011) Correlation of C4ST-1 and ChGn-2 expression with chondroitin sulfate chain elongation in atherosclerosis. Biochem Biophys Res Commun 406: 36-41.

6. Schonherr E, Jarvelainen HT, Kinsella MG, Sandell LJ, Wight TN (1993) Plateletderived growth factor and transforming growth factor-beta 1 differentially affect the synthesis of biglycan and decorin by monkey arterial smooth muscle cells. Arterioscler Thromb 13: 1026-1036.

7. Little PJ, Tannock L, Olin KL, Chait A, Wight TN (2002) Proteoglycans synthesized by arterial smooth muscle cells in the presence of transforming growth factor-beta1 exhibit increased binding to LDLs. Arterioscler Thromb Vasc Biol 22: 55-60.

8. Derynck R, Zhang YE (2003) Smad-dependent and Smad-independent pathways in TGF-beta family signalling. Nature 425: 577-584.

9. Massague J, Seoane J, Wotton D (2005) Smad transcription factors. Genes Dev 19: 2783-2810.

10. Dadlani H, Ballinger ML, Osman N, Getachew R, Little PJ (2008) Smad and p38 MAP kinase-mediated signaling of proteoglycan synthesis in vascular smooth muscle. J Biol Chem 283: 7844-7852.

11. Abrahamsen H, O'Neill AK, Kannan N, Kruse N, Taylor SS, et al. (2012) Peptidyl-prolyl isomerase Pin1 controls down-regulation of conventional protein kinase C isozymes. J Biol Chem 287: 13262-13278.

12. Kretzschmar M, Doody J, Timokhina I, Massague J (1999) A mechanism of repression of TGFbeta/ Smad signaling by oncogenic Ras. Genes Dev 13: 804816

13. Wrighton KH, Lin X, Feng XH (2009) Phospho-control of TGF-beta superfamily signaling. Cell Res 19: 8-20.
14. Susarla BT, Laing ED, Yu P, Katagiri Y, Geller HM, et al. (2011) Smad proteins differentially regulate transforming growth factor- $\beta$-mediated induction of chondroitin sulfate proteoglycans. J Neurochem 119: 868-878.

15. Reese S, Vidyasagar A, Jacobson L, Acun Z, Esnault S, et al. (2010) The Pin 1 inhibitor juglone attenuates kidney fibrogenesis via Pin 1-independen mechanisms in the unilateral ureteral occlusion model. Fibrogenesis Tissue Repair 3: 1.

16. Kobayashi K, Yokote K, Fujimoto M, Yamashita K, Sakamoto A, et al. (2005) Targeted disruption of TGF-beta-Smad3 signaling leads to enhanced neointimal hyperplasia with diminished matrix deposition in response to vascular injury. Circ Res 96: 904-912.

17. Aragon E, Goerner N, Zaromytidou Al, Xi Q, Escobedo A, et al. (2011) A Smad action turnover switch operated by WW domain readers of a phosphoserine code. Genes Dev 25: 1275-1288.

18. Matsuura I, Chiang KN, Lai CY, He D, Wang G, et al. (2010) Pin1 promotes transforming growth factor-beta-induced migration and invasion. J Biol Chem 285: $1754-1764$.

19. Kim SE, Lee MY, Lim SC, Hien TT, Kim JW, et al. (2010) Role of Pin1 in neointima formation: down-regulation of Nrf2-dependent heme oxygenase-1 expression by Pin1. Free Radic Biol Med 48: 1644-1653.

20. Cardoso LE, Little PJ, Ballinger ML, Chan CK, Braun KR, et al. (2010) Platelet-derived growth factor differentially regulates the expression and posttranslational modification of versican by arterial smooth muscle cells through distinct protein kinase $C$ and extracellular signal-regulated kinase pathways. $J$ Biol Chem 285: 6987-6995.

21. Ballinger ML, Ivey ME, Osman N, Thomas WG, Little PJ (2009) Endothelin-1 activates ETA receptors on human vascular smooth muscle cells to yield proteoglycans with increased binding to LDL. Atherosclerosis 205: 451-457.

22. Tickerhoof MM, Farrell PA, Korzick DH (2003) Alterations in rat coronary vasoreactivity and vascular protein kinase $\mathrm{C}$ isoforms in Type 1 diabetes. Am J Physiol Heart Circ Physiol 285: H2694-H2703.

23. Williams KJ, Tabas I (1995) The response-to-retention hypothesis of early atherogenesis. Arterioscler Thromb Vasc Biol 15: 551-561. 